\title{
Electrochemical behavior of anticancer drug 5-fluorouracil at carbon paste electrode and its analytical application
}

\author{
Shikandar D. Bukkitgar and Nagaraj P Shetti*
}

\begin{abstract}
Background: A set of pyrimidine nucleobase present in all living systems as a component of nucleic acid constitutes uracil together with thymine and cytosine. A diverse physiological activity is exhibited by many $\mathrm{N}$-substituted uracil derivatives. In oncology, 5-FU is widely used as an important anticancer drug.

Methods: Electrochemical behavior was studied using cyclic voltammetric method, and the analytical application was studied using differential pulse voltammetric method. Solution $\mathrm{pH}$ has been measured by $\mathrm{pH}$ meter.

Results: The process on the surface of electrode was found to be irreversible and diffusion controlled. The charge transfer coefficient, heterogeneous rate constant, and the number of electron transferred were calculated. Possible reaction mechanism taking place on the surface of electrode was proposed. Calibration plot constructed using differential pulse voltammetric technique was used for quantitative analysis in pharmaceutical and human urine sample. Limit of detection (LOD) and limit of quantification ( $L O Q$ ) were calculated to be 12.25 and $40.8 \mathrm{nM}$, respectively.

Conclusions: In the present work, we described the electrochemical behavior of anticancer drug and its determination in human urine and pharmaceutical samples. The method shows the development of a sensor for selective and sensitive determination of 5-FU.
\end{abstract}

Keywords: Electro-oxidation, Carbon paste electrode, 5-fluorouracil, Voltammetry, Pharmaceutical samples

\section{Background}

Ribonucleic acid consists of a pyrimidine base called uracil which forms base pair with adenine. For biosynthesis of nucleic acid in tumors, uracil is preferentially used (Rutman R.J. et al. 1954). A drastic change in the biological properties of uracil resulted from the substitution of hydrogen atom at fifth position by halogen atom (Voet D. and Voet J.G. 1995). Amongst the variety of uracil derivatives reported as antitumor and antiviral agent, 5-FU has acquired a position of particular importance. For the treatment of solid tumor of the breast and rectum, 5-FU has been used extensively as an antineoplastic agent (Heidlberg C. and Ansfield F.J. 1963). One of the major mechanisms responsible for antitumor activity of 5-FU is by inhibition of thymidylate synthesis (Hartmann K.U. and Heidelberger C. 1961). Detailed studies have pointed to 5 -FU interference

\footnotetext{
* Correspondence: npshetti@kleit.ac.in

Department of Chemistry, K.L.E Institute of Technology, Gokul Hubli-580030, Karnataka, India
}

\section{Springer}

(c) 2016 Bukkitgar and Shetti. Open Access This article is distributed under the terms of the Creative Commons Attribution 4.0 International License (http://creativecommons.org/licenses/by/4.0/), which permits unrestricted use, distribution, and reproduction in any medium, provided you give appropriate credit to the original author(s) and the source, provide a link to the Creative Commons license, and indicate if changes were made.

with DNA and protein synthesis, because of conversion to the corresponding ribose nucleoside and substitution into RNA, as an equally important mechanism of toxicity (Myers C.E. 1981). The studies on oxidation-reduction behavior of compounds of biological significance-is of considerable value, as they provide deep insight into the biological relevant redox reactions of these compounds. Although the actual biological redox reactions may be of more complexity due to enzymatic interactions, much more information can be derived from the study of these compounds in aqueous solution of known $\mathrm{pH}$.

Electrochemical methods have proved to be sensitive for the determination of organic molecules, including drugs and related molecules in pharmaceutical dosage forms and biological fluids and their oxidizable property (Padmini V. 2010; Hegde R.N et al. 2008). Carbon electrodes, especially paste electrodes, are widely used in the electrochemical investigations because of their low background current, wide potential windows, chemical 
inertness, low cost, and suitability for detection of various organic and biological compounds (Genxi L. and Peng M. 2013).

Many advantages such as very low background current, low cost, large potential window, simple surface renewal process, and easiness of miniaturization of carbon paste electrode (CPE) are widely applicable in both electrochemical studies and electroanalysis. In addition, easy fabrication of the electrode can be achieved by incorporating different substances during paste preparation which results in the so-called modified electrode with desired composition and predetermined properties (Khoobi A. et al. 2013; Mokhtari A. et al. 2012; Díaz C. et al. 2013; Gholivand M.B. and Mohammadi-Behzad L. 2014; MazloumArdakani M. et al. 2010; Raoof J.B et al. 2007; Dönmez S. et al. 2014).

According to the literature, no works are reported on voltammetric method for the determination of 5-FU at CPE. The focus behind this work is to develop a suitable experimental condition to investigate the electrochemical behavior of 5-FU and its determination in pharmaceutical sample and human urine sample. As compared to the other reported works, the sticking feature for this is, no prior extraction step is needed in urine analysis. In the present work, the electro organic reactions at the surface of electrodes and results of one more such study are presented. Here, we preferred to use bare CPE because of the strong adsorption of nitrogen atom on such material (Scheme 1).

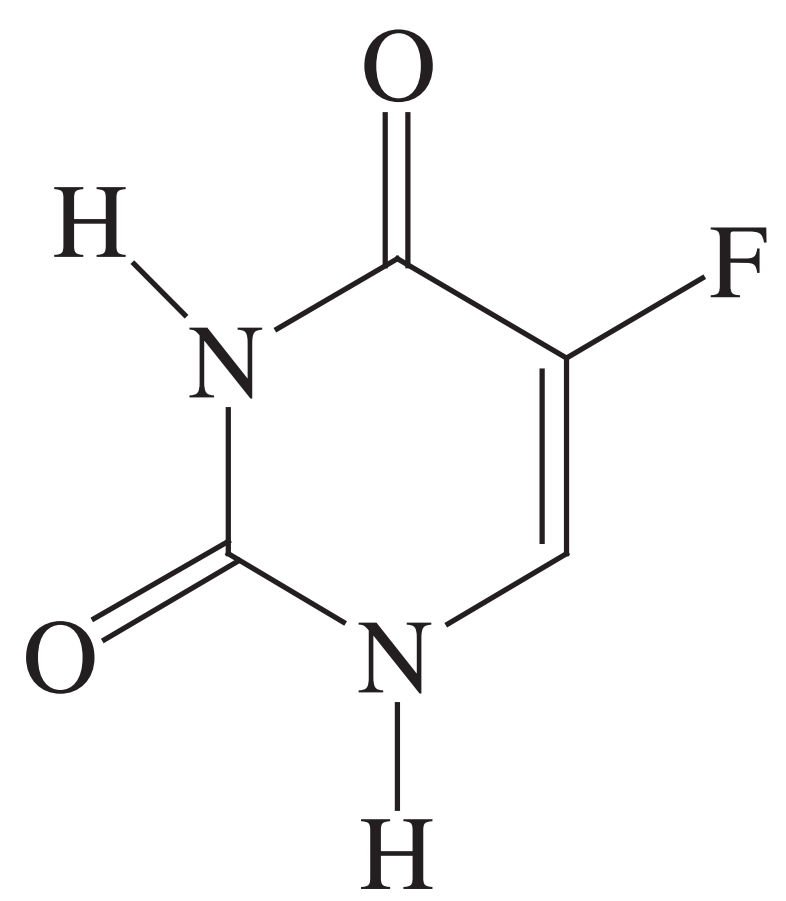

Scheme 1 Chemical structure of 5-FU

\section{Methods}

Apparatus and chemicals

Electrochemical analyzer (CHI Company, D630, USA) was used to study the electrochemical deeds of the drug under investigation at an ambient temperature of $25 \pm 0.1{ }^{\circ} \mathrm{C}$. A three-electrode system consisting of carbon paste electrode as working electrode, platinum wire as counter electrode, and $\mathrm{Ag} / \mathrm{AgCl}(3 \mathrm{M} \mathrm{KCl})$ as reference electrode were used in a 10-ml single compartment. In all the measurements, background subtraction was made. The phosphate buffer solutions ranging 3.0-11.2 $\mathrm{pH}(I=0.2)$ were prepared according to literature (Christian G.D. and Purdy W.C. 1962), and $\mathrm{pH}$ of the solutions was measured by $\mathrm{pH}$ meter (Elico Ltd., LI120, India). 5-FU (Sigma-Aldrich, USA) was used to prepare $1.0 \mathrm{mM}$ stock solution in double distilled water $\left(6.5 \times 10^{6} \Omega\right)$. Double distilled water and analytical grade chemicals and reagents without further purification were used throughout the experiments.

\section{Preparation of electrode}

The CPE was prepared by mixing $1.0 \mathrm{~g}$ of graphite powder and $0.5 \mathrm{ml}$ of paraffin oil in a small agate mortar, and this mixture was then homogenized. A portion of the resulting paste was packed firmly into a cavity of polytetrafluoroethylene tube (PTFE). The surface of the electrode was smoothed against weighing paper and rinsed with water. The paste was carefully removed prior to pressing a new portion in to the electrode after every measurement. The resulting electrode was noted as CPE. Prior to use, the CPE was activated in phosphate buffer solution of $\mathrm{pH} 7$ by cyclic voltammetric sweeps between 0.4 and $1.4 \mathrm{~V}$ with a scan rate $50 \mathrm{mVS}^{-1}$. (Malode S.J. et al. 2013).

Randles-Sevcik formula can be used to calculate the electro-active area of the electrode using cyclic voltammetric technique and $\mathrm{K}_{3} \mathrm{Fe}(\mathrm{CN})_{6} 1.0 \mathrm{mM}$ as a probe at different scan rates in $0.1 \mathrm{M} \mathrm{KCl}$ as supporting electrolyte. At $\mathrm{T}=298 \mathrm{~K}$ and for a reversible process, the equation is as follows (Malode S.J. et al. 2012):

$$
\text { Ip }=\left(2.69 \times 10^{5}\right) n^{3 / 2} A_{0} D_{\mathrm{R}}{ }^{1 / 2} v^{1 / 2} C_{0}
$$

In Eq. (1), for $1.0 \mathrm{mM} \mathrm{K} \mathrm{K}_{3} \mathrm{Fe}(\mathrm{CN})_{6}$ and $0.1 \mathrm{M} \mathrm{KCl}$ as supporting electrolyte, Ip refers to the anodic peak current, $n$ is the number of electron transferred during the electrode reaction equal to $1 . A_{0}$ is the surface area of the electrode, $D_{\mathrm{R}}$ is the diffusion coefficient equal to $7.6 \times 10^{-6} \mathrm{~cm}^{2} \mathrm{~s}^{-1}, v$ is the scan rate, and $C_{0}$ is the concentration of $\mathrm{K}_{3} \mathrm{Fe}(\mathrm{CN})_{6}$. From the slope of the plot of Ip vs. $v^{1 / 2}$, the area of the electrode surface was calculated to be $0.036 \pm 0.0014 \mathrm{~cm}^{2}$. 


\section{Sample preparation}

To carry out the pharmaceutical analysis, 5-FU tablets were grounded using a mortar and a fraction corresponding to stock solution of $1 \mathrm{mM}$ was weighed and completed to the volume with double distilled water in a $100-\mathrm{ml}$ calibrated flask. After sonication for $10 \mathrm{~min}$, to affect complete dissolution suitable aliquots of the clear supernatant, liquid was taken and diluted with buffer solution of $\mathrm{pH}$ 7. The oxidation peak current of 5-FU was measured using differential pulse voltammetric technique. Standard addition method was to study the accuracy of the projected method and the interference from excipients used in dose forms.

\section{Results and discussion}

Electrochemical behavior of 5 -FU

In order to understand the electrochemical behavior of 5-FU, cyclic voltammetric technique was used. Between the range 3.0-11.2 pH, one well-defined irreversible oxidation peak was observed. In Fig. 1, voltammetric behavior of 5-FU in phosphate buffer solution $(\mathrm{pH}=7, I=0.2)$ is represented, curve (a) corresponds to buffer solution and (b) anodic peak corresponding to 5-FU oxidation. There was no peak observed on the reverse scan, therefore electrode process is supposed to be irreversible. Since successive cyclic voltammogram showed a decrease in the peak current due to adsorption of 5-FU or its oxidation product, the oxidation peak corresponding to the first sweep was only recorded.

\section{Influence of accumulation time}

Peak current can be greatly affected by the adsorption of analyte on the surface of the electrode. It is important to fix the accumulation time to improve the sensitivity of the electrode towards the analyte. Open circuit accumulation with cyclic voltammetric technique was use to study the effect of accumulation time on peak current (Fig 2). The effect of accumulation time was studied in the range of 0-150 s. One hundred twenty seconds was employed as optimal accumulation time in further experiments since maximum peak current was observed at $120 \mathrm{~s}$.

\section{Effect of supporting electrolyte}

Electrochemical behavior of the analyte under investigation strongly depends on the $\mathrm{pH}$ of the solution. By optimizing the $\mathrm{pH}$ conditions, sharper response accompanied with higher sensitivity can be obtained. Hence, phosphate buffer solution over the $\mathrm{pH}$ range 3.0-11.2 was used to study the electrochemical behavior of 5-FU (Fig 3). It was observed that the peak potential shifted to less positive values with increase in the $\mathrm{pH}$ of the buffer solution (Fig. 3(A)). The linear relationship between Ep and $\mathrm{pH}$ can be expressed as follows:

$$
\operatorname{Ep}(V)=-0.0595 \mathrm{pH}(V)+1.5652: R^{2}=0.9952
$$

From the plot of Ip vs. pH (Fig. 3(B)), it is clear that the best result with respect to sensitivity accompanied

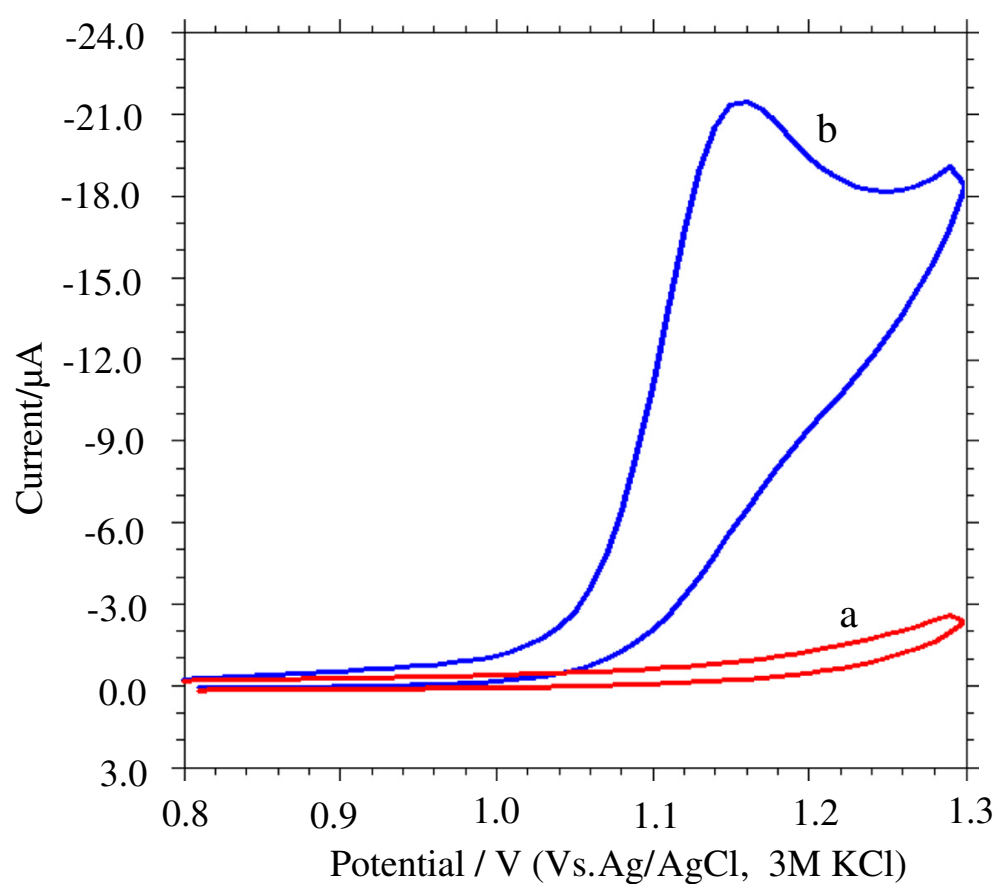

Fig. 1 Cyclic voltammogram behavior of 5-FU, phosphate buffer ( $\mathrm{pH}=7, \mathrm{I}=0.2 \mathrm{M})$, (a) blank carbon paste electrode, and (b) carbon paste electrode $1.0 \times 10^{-4} \mathrm{M}$; 5 -FU scan rate: $50 \mathrm{mVs}^{-1}$; accumulation time: $120 \mathrm{~s}$ (at open circuit) 


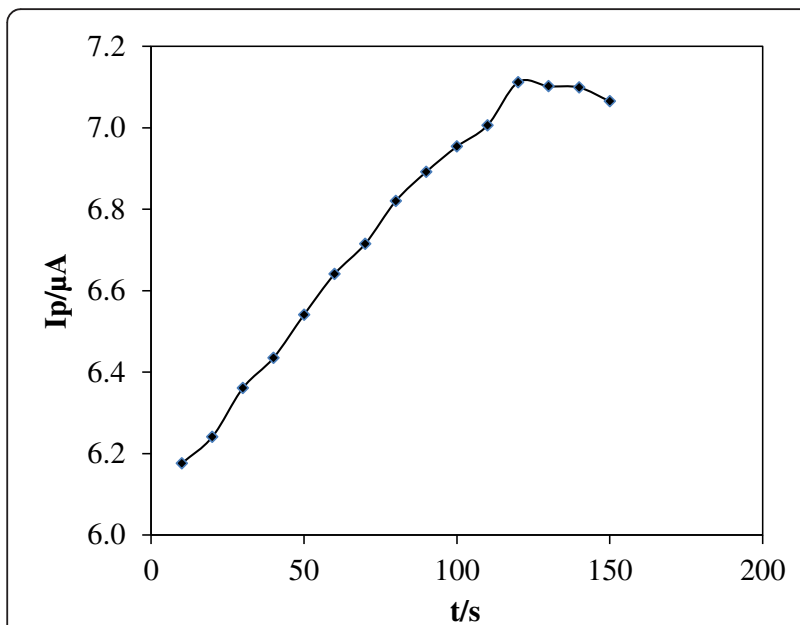

Fig. 2 Variation of the cyclic voltammetric anodic peak current with accumulation time with sharper response was obtained with $\mathrm{pH}=7.0$, hence, it was selected for further work (Hegde R. N. et al. 2009). The peak current depends on the deprotonation and protonation form of the electro-active species in electrochemical cell. At $\mathrm{pH} 7$, protonated and deprotonated form of 5-FU dominates. And a gradual change of speciation of 5-FU occurs in the $\mathrm{pH}$ range 7 to 9 . Further, the magnitude of current is directly proportional to the rate of the electrochemical reaction. Hence, it is apparent to conclude that the oxidation of 5 -FU is very high at $\mathrm{pH} 7$ (Ioana P. et al. 2005).

\section{Influence of scan rate}

Relationship between peak current and scan rate gives constructive information about electrochemical mechanism. At different scan rates, the electrochemical behavior of 5 -FU was studied by using cyclic voltammetric technique (Fig. 4). The dependence of the peak intensity Ip $(\mu \mathrm{A})$ upon the scan rate $v\left(\mathrm{Vs}^{-1}\right)$ (Fig. 4(A)) was carried out to assess whether the

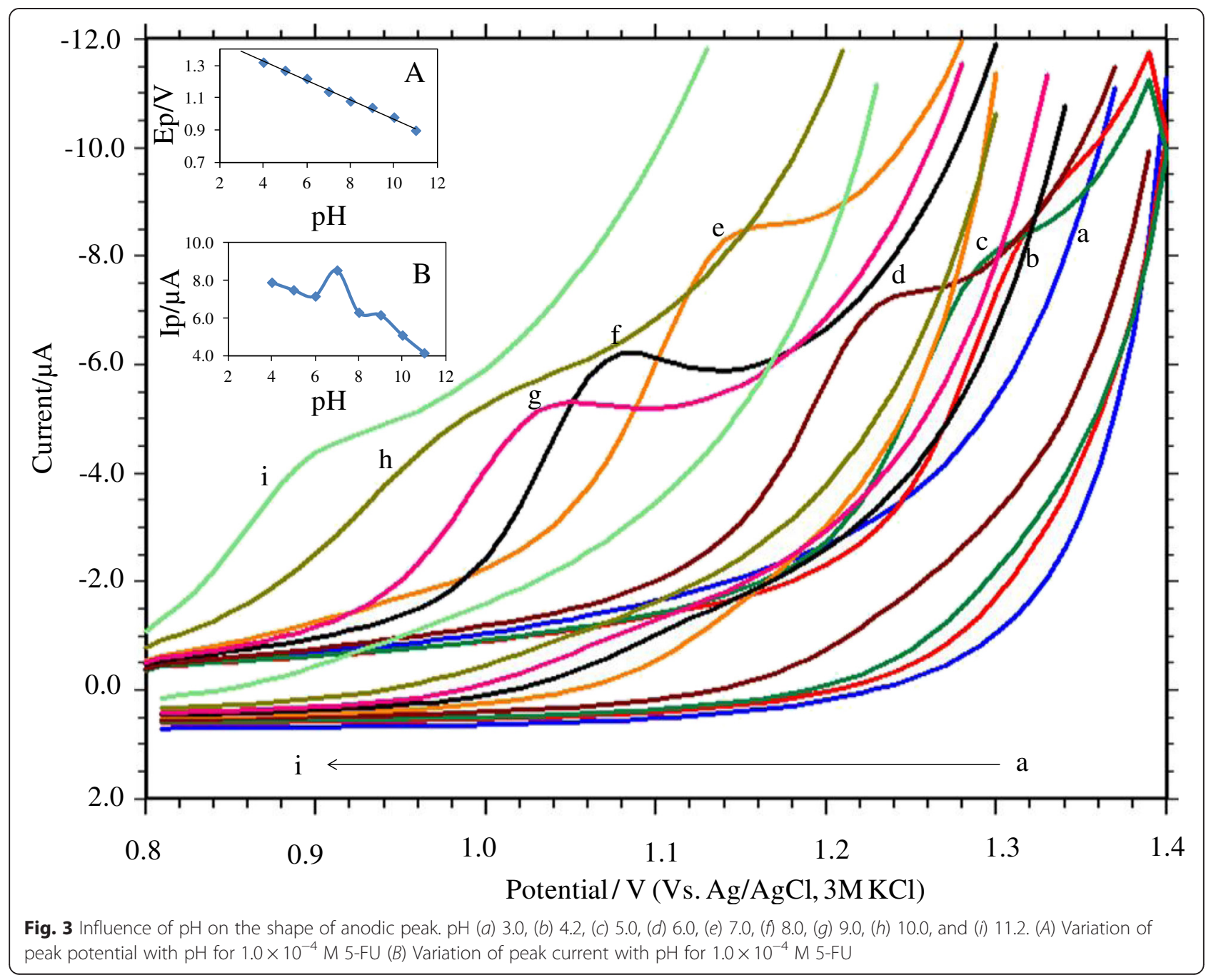




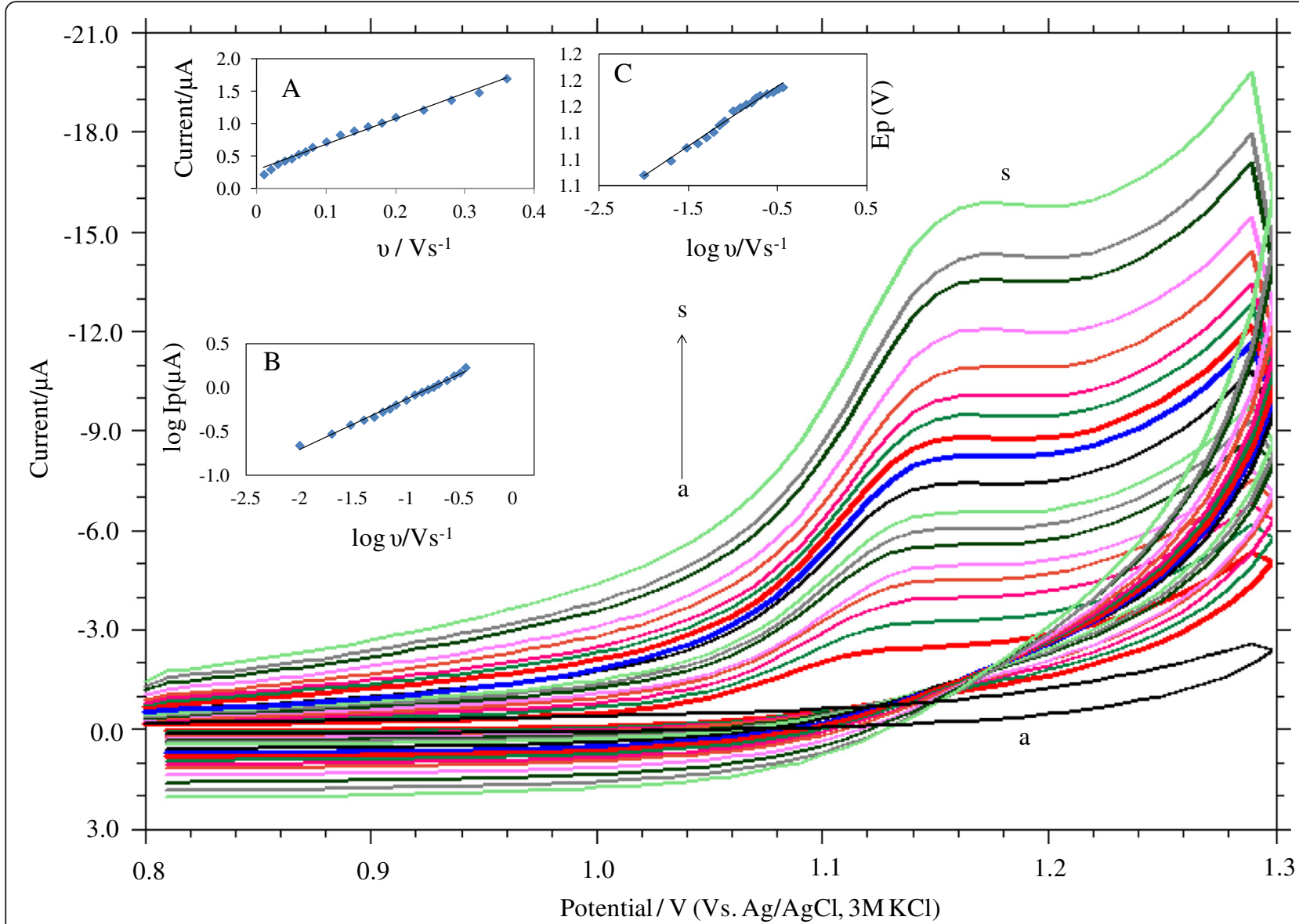

Fig. 4 Cyclic voltammograms of $1.0 \times 10^{-4} \mathrm{M} 5-\mathrm{FU}$ in $0.2 \mathrm{M}$ buffer solution at pH 7.0 at scan rates of (a) blank, (b) 0.01, (c) 0.02, (d) 0.03, (e) 0.04, (f) 0.05, (g) 0.06, (h) 0.07, (i) 0.08, (j) 0.10, (k) 0.12, (l) 0.14, (m) 0.16, (n) 0.18, (o) 0.20, (p) 0.24, (q) 0.28, (r) 0.32, and (s) 0.36 Vs ${ }^{-1}$. (A) Dependence of peak current on the scan rate $\left(y=3.9616 x+0.2793: R^{2}=0.9884\right)$. (B) Dependence of logarithm of peak current on logarithm of scan rate $(y=0.571 x+0.4405$ : $\left.R^{2}=0.9939\right)$. (C) Relationship between peak potential and logarithm of scan rate $\left(y=0.0457 x+1.1984: R^{2}=0.9877\right)$

process on carbon paste electrode was under diffusion or adsorption-controlled. A linear relationship which is of typical diffusion controlled process was observed for the influence of square root of scan rate on peak potential, and the equation can be expressed as follows:

$$
\operatorname{Ip}(\mu \mathrm{A})=28433 v^{1 / 2}\left(\mathrm{mVs}^{-1}\right)-0.1465: R^{2}=0.9877
$$

Straight line with a slope of 0.57 (Fig. 4(B)) closer to the theoretical value of 0.5 for a purely diffusion controlled process was obtained for the plot, logarithm of anodic peak current vs. logarithm of scan rate (Malode S.J (b) et al. 2012), corresponding to the following equation:

$\log \mathrm{Ip}(\mu \mathrm{A})=571.7 \log v\left(\mathrm{mVs}^{-1}\right)+0.4405:$

$$
R^{2}=0.9939
$$

And also, the peak potential shifted to more positive values on increasing the scan rate, which confirms the irreversibility of the oxidation process (Brown E.R. and Large R.F. 1964), and a linear relationship between peak potential and logarithm of scan rate (Fig. $4(\mathrm{C})$ ) can be expressed by the following equation:

$\operatorname{Ep}(V)=45.7 \log v\left(\mathrm{mVs}^{-1}\right)+1.1984: R^{2}=0.9877$

For an irreversible electrode process, according to Laviron (Laviron E. 1979), Ep is defined by the following equation;

$$
\mathrm{Ep}=E^{0}+\left(\frac{2.303 R T}{\alpha n F}\right) \log \left(\frac{R T k^{0}}{\alpha n F}\right)+\left(\frac{2.303 R T}{\alpha n F}\right) \log v
$$

Where $\alpha$ is the transfer coefficient, $k^{0}$ is the standard heterogeneous rate constant of the reaction, $n$ is the number of electron transferred, $v$ is the scan rate, and $E^{0}$ is redox potential. From the slope of $E_{\mathrm{p}}$ versus $\log v$, value of $\alpha n$ can be calculated. Taking $T=298 \mathrm{~K}, R=8.314 \mathrm{JK}^{-1} \mathrm{~mol}^{-1}$, and $\mathrm{F}=96,480 \mathrm{C} \mathrm{mol}^{-1}$, the value of $\alpha n$ was calculated to be 
1.2. According to Bard and Faulkner, (Allen J. B. and Larry R.F. 2004) $\alpha$ can be calculated as

$$
\alpha=\frac{47.7}{E_{\mathrm{p}}-E_{\mathrm{p} / 2}} \mathrm{mV}
$$

Where $E_{\mathrm{p} / 2}$ is the potential where the current is at half the peak value. From the above equation, value of $\alpha$ was to be 0.56 . The number of electrons transferred in electrode oxidation was calculated to be $2.3 \approx 2$. Hence, 5 -FU may be assumed to undergo two protons and two electron transfer in the electrode reaction. If the value of $E^{0}$ is known, the value of $k^{0}$ can be determined from the intercept of the above plot. From the intercept of Ep versus $v$ curve by extrapolating to the vertical axis, at $v=0$, the value of $E^{0}$ can be calculated from Eq. 2 (Shetti N.P. et al. 2012). From the intercept of Ep versus $\log v$ which was found to be 1.199, $E^{0}$ and $k^{0}$ were calculated to be 1.13 and $1.7 \times 10^{3} \mathrm{~s}^{-1}$, respectively.

\section{Reaction mechanism}

Electrochemical oxidation of 5-FU proceeds with the removal of two electrons and two protons. In the first step, removal of $\pi$-electrons from the ring to give species (1) takes place. As the species (1) is highly unstable, it is readily attacked by $\mathrm{OH}^{-}$ions to give species (2). Further removal of one proton and one electron gives the final product. The oxidation of $\mathrm{C}=\mathrm{C}$ depends on the electron density available at $\pi$-bond. The introduction of electron withdrawing group at the fifth position may exert a pull on the electrons of $\pi$-bond due to inductive effect and therefore the electron density may decrease. However, the mesomeric effect of halogen atom plays an important role, and electron density increases at $\pi$-bond and hence oxidation becomes easy. Scheme 2

\section{Concentration variation}

Since differential pulse voltammetry technique gave sharper and well-defined peaks even at low concentration of 5-FU, it was preferred to develop a voltammetric technique for determination of 5-FU. The phosphate buffer solution of $\mathrm{pH}=7.0$ was selected as the supporting electrolyte for the quantitative determination of 5-FU. Differential pulse voltammograms obtained with increasing amounts of $5-\mathrm{FU}$ as shown in Fig. 5. In the range of $1 \times 10^{-7}-4 \times 10^{-5} \mathrm{M}$ linear calibration curves were obtained for 5 -FU. The linear equation was<smiles>C[I+]#[I-]</smiles>

5- FU<smiles>O=C1NCC(F)C(=O)N1</smiles>

(1)

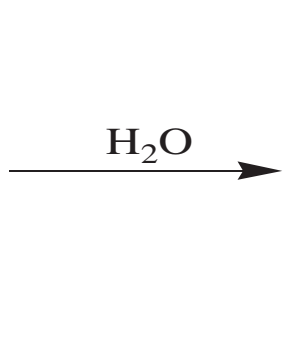<smiles>O=C1NC(=O)C(F)C(O)N1</smiles>

(2)

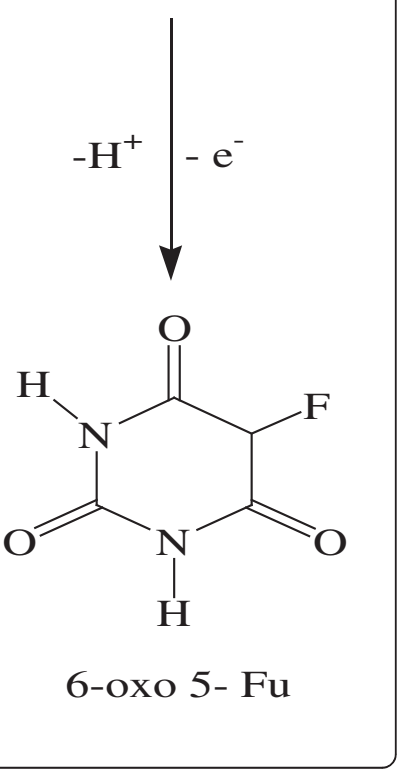




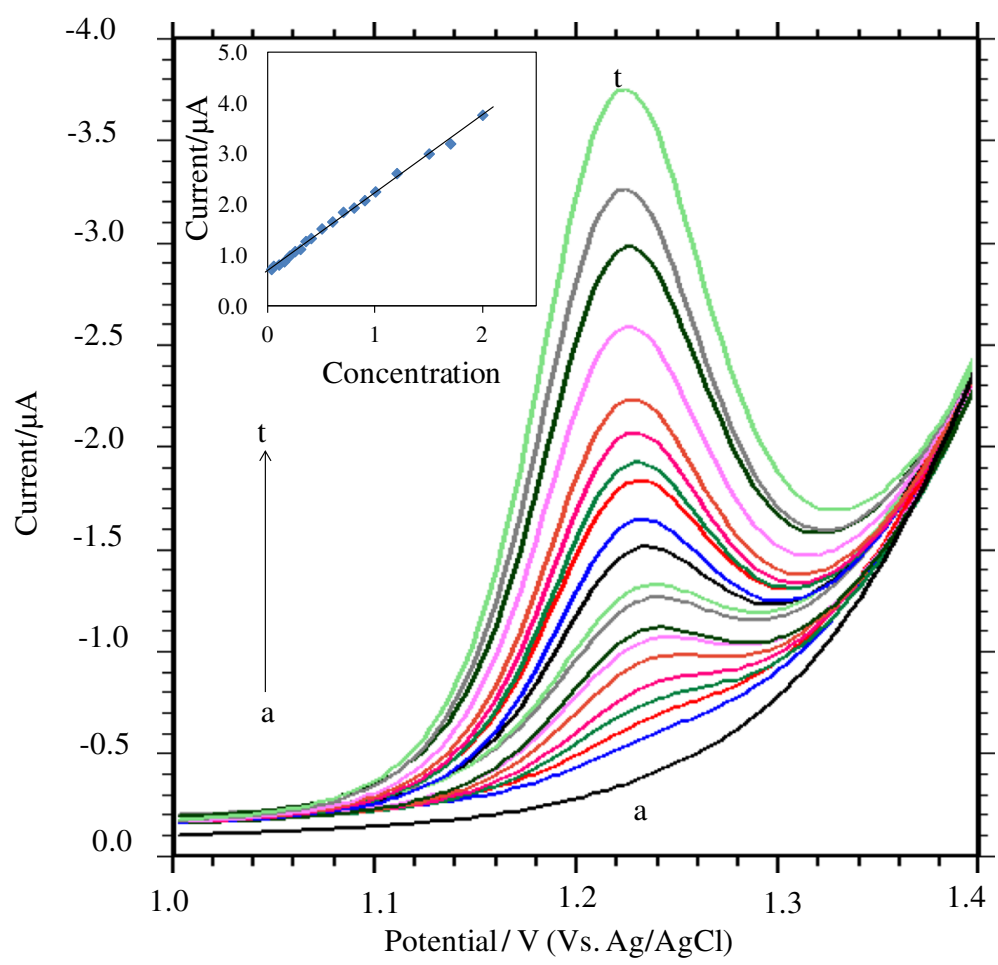

Fig. 5 Differential pulse voltamogramms of 5-FU at carbon paste electrode at different concentrations (a) blank, (b) 3, (c) 5, (d) 10, (e) 15, (f) 20, (g) 25, (h) 30, (i) 35, (j) 40, (k) 50, (l) 60, (m) 70, (n) 80, (o) 90, (p) 100, (q) 120, (r) 150, (s) 170, and (t) $200 \mu \mathrm{M}$. (A) Plot of current vs. concentration of 5 -FU

$$
\mathrm{Ip} / \mu \mathrm{A}=1.5301 c+0.7042: R^{2}=0.9974
$$

The adsorption of 5-FU or its oxidation product on the electrode surface deviates the linearity for more concentrated solution. Five different determinations were used to develop the statistical data related to calibration curve (Table 1). Limit of detection (LOD) and limit of quantification (LOQ) were calculated to be 12.25 and $40.8 \mathrm{nM}$, using following equation (Shetti N.P. et al. 2009)

Table 1 Characteristics of 5-fluorouracil calibration plot using differential pulse voltammetry at carbon paste electrode

\begin{tabular}{lc}
\hline Linearity range $(\mathrm{M})$ & $1 \times 10^{-7}$ to $4 \times 10^{-5} \mathrm{M}$ \\
\hline Slope of the calibration plot $\left(\mu \mathrm{A} \mathrm{M}^{-1}\right)$ & 1.530 \\
Intercept $(\mu \mathrm{A})$ & 0.704 \\
Correlation coefficient $(\mathrm{r})$ & 0.997 \\
RSD of slope (\%) & 0.88 \\
RSD of intercept (\%) & 0.87 \\
Number of data points & 19 \\
LOD (M) & $12.25 \mathrm{nM}$ \\
LOQ (M) & $40.8 \mathrm{nM}$ \\
Repeatability (RSD \%) & 1.6 \\
Reproducibility (RSD \%) & 2.7 \\
\hline
\end{tabular}

$$
\mathrm{LOD}=3 \mathrm{~S} / m \cdots ; \cdots \mathrm{LOQ}=10 \mathrm{~S} / m
$$

$S$ is the standard deviation of the peak currents and $m$ is the slope of calibration curve. The detection limits reported at different methods for 5-FU are tabulated in the Table 2. This method was better as compared to other reported methods (Hua X. et al 2013; Sataraddi S. R. and Nandibewoor S. T. 2011; Badea I. et al. 2002; Fars K.A et al. 2009; Tianrong Z. et al. 2011). Repeatability of the electrode renewed every time was studied for every

Table 2 Comparison of detection limits of 5-fluorouracil by different reported methods

\begin{tabular}{lcl}
\hline Method & LOD (nM) & Reference \\
\hline $\begin{array}{l}\text { Glassy carbon electrode modified } \\
\text { with bromothymol blue and }\end{array}$ & 267 & Hua X. et al 2013 \\
$\begin{array}{l}\text { multi-walled carbon nano-tube } \\
\begin{array}{l}\text { Glassy carbon electrode mediated } \\
\text { by surfactant cetyltrimethyl }\end{array}\end{array}$ & 20.1 & Sataraddi S. R. and \\
$\begin{array}{l}\text { ammonium bromide } \\
\text { Spectrometry }\end{array}$ & & Nandibewoor S. T 2011 \\
$\begin{array}{l}\text { HPLC } \\
\text { lonic liquid modified carbon paste } \\
\text { electrode }\end{array}$ & 130.69 & Badea I. et al. 2002 \\
Carbon paste electrode & 70.89 & Fars K.A. et al. 2009 \\
\hline
\end{tabular}


Table 3 Analysis of 5-fluorouracil in tablets by differential pulse voltammetry and recovery studies

\begin{tabular}{ll}
\hline Labeled claim & 100 \\
\hline Amount found $(\mathrm{mg})^{\mathrm{a}}$ & 96.72 \\
RSD (\%) & 3.7 \\
$t$ test of significant & 0.43 \\
F test of significant & 0.96 \\
Bias (\%) & 2.3 \\
Added (mg) & 1 \\
Found (mg) & 0.97 \\
Recovered (\%) & 97 \\
RSD (\%) & 1.6 \\
Bias (\%) & -3.0 \\
\hline
\end{tabular}

${ }^{\mathrm{a}}$ Average of five determinations

several hours within a day, and percentage RSD has been calculated to be $1.6 \%$. As to the reproducibility between days, it was similar to that of within day repeatability if, the temperature was kept almost unchanged. The reproducibility RSD has been calculated to be $2.7 \%$.

\section{Tablet analysis and recovery test}

Commercially available tablets were used for the analysis of 5-FU recovery test was carried using standard addition method. Grounding the tablets to powder and dissolving it in distilled water, the concentration of 5-FU tablet was prepared in such a way that they fall in the range of calibration plot. The proposed procedure was applied to the analysis of 5-FU in commercially available tablets. Standard addition method was used, and the recovery studies were performed. Identical conditions were employed for the analysis of the tablet as used for plotting calibration plot. Differential pulse voltammetry technique was used, and results obtained were having good agreement with the content marked in the label. In different sample, the recoveries lie between 93.9 and $99.3 \%$ with RSD of $2.1 \%$ (Table 3 ).

Table 4 Influence of potential interferents on the voltammetric response of $1.0 \times 10^{-4} \mathrm{M} 5$-fluorouracil

\begin{tabular}{lll}
\hline Interferent & Concentration & Signal change (\%) \\
\hline Oxalic acid & 0.1 & 0.87 \\
Citric acid & 0.1 & 2.66 \\
Lactose & 0.1 & -1.70 \\
Sucrose & 0.1 & -0.85 \\
Dextrose & 0.1 & 1.75 \\
Glucose & 0.1 & 2.47 \\
Gum acacia & 0.1 & -3.41 \\
Starch & 0.1 & 0.95 \\
\hline
\end{tabular}

Table 5 Application of differential pulse for the determination of 5-fluorouracil in spiked human urine

\begin{tabular}{llll}
\hline Urine spiked $\left(10^{-5} \mathrm{M}\right)$ & Detected $^{\mathrm{a}}\left(10^{-5} \mathrm{M}\right)$ & Recovery $(\%)$ & RSD (\%) \\
\hline Urine sample 1 & 0.1 & 98.5 & 2.9 \\
Urine sample 2 & 0.2 & 92.8 & 3.1 \\
Urine sample 3 & 0.5 & 99.5 & 2.9 \\
Urine sample 4 & 0.8 & 99.9 & 2.9 \\
Urine sample 5 & 1.0 & 96.6 & 3.0 \\
\hline
\end{tabular}

${ }^{\mathrm{a}}$ Average of five determinations

\section{Effect of interferents}

To evaluate the effect of interferents, $0.1 \mathrm{mM} 5$-FU was used. The Table 4 shows that 100 -fold of citric acid, gum acacia, oxalic acid, sucrose, and urea did not interfere with the voltammetric signal of 5 -FU. The tolerance limit was less $\pm 5 \%$. The tolerance limit is defined as the maximum concentration of the interfering substance that caused error less than $\pm 5 \%$ for determination of 5 -FU.

\section{Urine analysis and recovery test}

For the determination of 5-FU in human urine sample differential pulse, voltammetric technique was used. Drugfree human urine samples were obtained from healthy volunteers who gave their informed consent, filtered through a filter paper, and stored frozen until the assay was carried out. The study was approved by the Institutional Review Committee of K. L. E. Institute of Technology (KLEIT/ IRC/2015-16/01). By spiking the drug-free urine sample with known amount of drug, the recovery study was carried out. For the determination of spiked 5-FU in urine sample, calibration graph was used. Five urine samples were used for the detection, and obtained results are tabulated in Table 5. The recovery determination was in the range from 92.8 to $99.9 \%$ with RSD of $2.97 \%$.

\section{Conclusions}

In the present work, oxidation of 5-FU in phosphate buffer solution $(\mathrm{pH}=7)$ was successfully carried out. The electrode process of 5 -FU is diffusion-controlled and irreversible. Suitable electrode reaction mechanism was proposed. A differential pulse voltammetric technique was developed for the determination of 5 -FU in pharmaceutical dose and human urine samples. As compared to other methods, the proposed method offered an improvement in simplicity and accuracy.

\section{Competing interests \\ The authors declare that they have no competing interests}

\section{Authors' contributions}

NPS and SDB designed the experiment and drafted the manuscript. Experimental part and calculations were carried out by SDB. NPS is the corresponding author. All the authors have read and approved the final manuscript. 
Received: 19 May 2015 Accepted: 20 December 2015

Published online: 11 January 2016

\section{References}

Allen JB, Larry RF. Electrochemical methods: fundamentals and applications. 2nd ed. New York: John Wiley and sons; 2004

Badea I, Moja D, Tudose A, Stoicescu D. Determination of the 5-fluorouracil and $\mathrm{N} 1\left(2^{\prime}\right.$-furanidyl)uracil in the presence of tegafur by zero-crossing first derivative spectrometry. J Pharm Biomed Anal. 2002;30:1371.

Brown ER, Large RF, Weissberger A, Rossiter BW. Physical methods of chemistry. New York: Wiley Interscience. Rochester; 1964.

Christian GD, Purdy WC. The residual current in orthophosphate medium. J Electroanal Chem. 1962;3:363.

Díaz C, García C, Iturriaga-Vásquez P, Jesús Aguirre M, Pablo Muena J, Contreras $R$, et al. Experimental and theoretical study on the oxidation mechanism of dopamine in n-octyl pyridinium based ionic liquids-carbon paste modified electrodes. Electrochimi Acta. 2013;111:846.

Dönmez S, Arslan F, Sarı N, Kurnaz Yetim N, Arslan H. Preparation of carbon paste electrodes including poly(styrene) attached glycine-Pt(IV) for amperometric detection of glucose. Biosens Bioelectron. 2014;54:146.

Fars KA, Alaa EY, Mahmoud E-B, Hammam AM, Ibrahim AA. Validated highperformance liquid chromatographic technique for determination of 5-fluorouracil: applications to stability studies and simulated colonic media. J Chromatographic Science. 2009; 47:558.

Genxi L, Peng M. Electrochemical analysis of proteins and cells. Berlin Heidelberg: Springer; 2013

Gholivand MB, Mohammadi-Behzad L. Fabrication of a highly sensitive sumatriptan sensor based on ultrasonic-electrodeposition of Pt nanoparticles on the $\mathrm{ZrO}_{2}$ nanoparticles modified carbon paste electrode. J Electroanal Chem. 2014;712:33.

Hartmann KU, Heidelberger C. Studies on fluorinated pyrimidines: XIII. Inhibition of thymidylate synthetase. J Biol Chem. 1961;236:3006.

Hegde RN, Nandibewoor ST. Electrochemical oxidation of pentoxifylline and its analysis in pure and pharmaceutical formulations at a glassy carbon electrode. Anal Lett. 2008;41:977.

Hegde RN, Kumara Swamy BE, Shetti NP, Nandibewoor ST. Electro-oxidation and determination of gabapentin at gold electrode. J Electroanal Chem. 2009;635:51.

Heidlberg C, Ansfield FJ. Experimental and clinical use of fluorinated pyrimidines in cancer chemotherapy. Cancer Res. 1963;23:1226.

Hua X, Xiaolan H, Gong X, Shen G. Electrochemical behavior of 5-fluorouracil on a glassy carbon electrode modified with bromothymol blue and multi-walled carbon nanotubes. Anal Methods. 2013;5:2470.

loana P, Smaranda C, Simona CP, Wolfgang K. Raman, surface enhanced Raman spectroscopy, and DFT calculations: a powerful approach for the identification and characterization of 5-fluorouracil anticarcinogenic drug species. J Phys Chem A. 2005;109:9945.

Khoobi A, Ghoreishi SM, Masoum S, Behpour M. Multivariate curve resolutionalternating least squares assisted by voltammetry for simultaneous determination of betaxolol and atenolol using carbon nanotube paste electrode. Bioelectrochemistry. 2013;94:100.

Laviron E. General expression of the linear potential sweep voltammogram in the case of diffusion less electrochemical systems. J Electroanal Chem. 1979;101:19.

Malode SJ, Nandibewoor ST. Electrochemical oxidation and determination of nimesulide using a carbon paste electrode. Z Phys Chem. 2013;227:73.

Malode SJ, Abbar JC, Shetti NP, Nandibewoor ST. Voltammetric oxidation and determination of loop diuretic furosemide at a multi-walled carbon nanotubes paste electrode. Electrochim Acta. 2012a;60:95.

Malode SJ, Shetti NP, Nandibewoor ST. Voltammetric behavior of theophylline and its determination at multi-wall carbon nanotube paste electrode. Colloids Surf B: Biointerfaces. 2012b;97:1.

Mazloum-Ardakani M, Beitollahi H, Amini MK, Mirkhalaf F, Abdollahi-Alibeik M. New strategy for simultaneous and selective voltammetric determination of norepinephrine, acetaminophen and folic acid using $\mathrm{ZrO}_{2}$ nanoparticles modified carbon paste electrode. Sens Actuators B. 2010;151:243.

Mokhtari A, Karimi-Maleh H, Ensafi AA, Beitollahi H. Application of modified multiwall carbon nanotubes paste electrode for simultaneous voltammetric determination of morphine and diclofenac in biological and pharmaceutical samples. Sens Actuators B. 2012;169:96.

Myers CE. The pharmacology of the fluoropyrimidines. Pharmacol Rev. 1981;33:1.

Padmini V. Synthesis and characterization of new Schiff's bases containing an azo group. Archives of Applied Science Research. 2010;2:356.
Raoof JB, Ojani R, Beitollahi H. L-cysteine voltammetry at a carbon paste electrode bulk-modified with ferrocenedicarboxylic acid. Electroanalysis. 2007;19:1822.

Rutman RJ, Cantarow A, Paschkis KE. Studies in 2-acetylaminofluorene carcinogenesis: III. The utilization of uracil-2-C14 by preneoplastic rat liver and rat hepatoma. Cancer Res. 1954;14:119.

Sataraddi SR, Nandibewoor ST. Voltammetric-oxidation and determination of 5flurouracil and its analysis in pharmaceuticals and biological fluids at glassy carbon electrode mediated by surfactant cetyltrimethyl ammonium bromide. Der pharma chemica. 2011;3:253.

Shetti NP, Sampangi LV, Hegde RN, Nandibewoor ST. Electrochemical oxidation of loop diuretic furosemide at gold electrode and its analytical applications. Int J Electrochem Sci. 2009;4:104.

Shetti NP, Malode SJ, Nandibewoor ST. Electrochemical behavior of an antiviral drug acyclovir at fullerene-C60-modified glassy carbon electrode. Bioelechem. 2012;88:76.

Tianrong Z, Lili C, Wei S, Wanguo H. Electrochemical behavior of 5-fluoro-1Hpyrimidine-2 on an ionic liquid modified carbon paste electrode. Analytical Methods. 2011;3:2651.

Voet D, Voet JG. Biochemistry. 2nd ed. New York: John Wiley, and sons; 1995.

\section{Submit your manuscript to a SpringerOpen ${ }^{\circ}$ journal and benefit from:}

- Convenient online submission

- Rigorous peer review

- Immediate publication on acceptance

- Open access: articles freely available online

- High visibility within the field

- Retaining the copyright to your article

Submit your next manuscript at $\boldsymbol{\wedge}$ springeropen.com 